\title{
Entitlement and Free Time ${ }^{1}$
}

\author{
ROSA TERLAZZO \\ Kansas State University
}

\begin{abstract}
In this paper, I use the framework developed by Julie Rose in Free Time to offer an initial analysis of another under-theorized resource that liberal egalitarian states might owe their citizens: that is, the sense of moral entitlement to make use of their basic liberties. First, I suggest that this sense of moral entitlement, like free time, might be necessary for the effective use of those basic liberties. Next, I suggest that this sense of moral entitlement (again, like free time) might be the kind of all-purpose good that satisfies publicity and feasibility criteria. Together, this suggests that a sense of moral entitlement to make use of basic liberties is the kind of resource that is appropriate for distribution by a liberal egalitarian state, and that such states indeed owe their citizens.
\end{abstract}

Keywords: effective freedom; free time; moral entitlement; resource

In her excellent book Free Time, Julie Rose offers an extensive analysis of the under-theorized resource of free time. In it, she argues for two main conclusions: first, that free time has the requisite features to count as a distributable resource within a liberal egalitarian theory of justice; and second, that liberal egalitarian states have an obligation to fairly distribute free time to citizens, on the grounds that free time is necessary to guarantee the effective use of the other basic liberties. While Rose's substantive discussion of free time is clearly her book's most significant contribution to political philosophy, I focus here on another of its valuable features: the way in which her argument serves as both a model for exploring other under-theorized resources that liberal states owe their citizens, and a reminder of the importance of developing comprehensive accounts of these other resources.

In this paper, I use Rose's strategy, along with the structure of her argument and insights from her broader discussion, to run a parallel

1 For helpful comments, I am grateful to Timothy Fowler, Jonathan Herington, Tom Parr, Chad Van Schoelandt, and the Editor and an anonymous referee for this journal. 
argument that justice might also require the fair distribution among citizens of a sense of moral entitlement to make use of one's basic liberties. In a paper of this length, however, I can only offer a rough and initial argument, noting only in passing where points are controversial or require further development. Like free time and justice, giving a full account of the relationship between justice and a sense of moral entitlement would require a book-length treatment.

\section{FREE TIME, A SENSE OF MORAL ENTITLEMENT, AND EFFECTIVE USE OF THE BASIC LIBERTIES}

Like Rose I take it for granted that liberal egalitarians must be committed to ensuring the effective use of the freedoms and opportunities they distribute among citizens (2016:69-73). While differentliberal egalitarians may specify the principle differently, I will use the following general formulation:

Effective Freedoms Principle: The liberal egalitarian state has an obligation to ensure citizens the effective rather than merely formal use of some centrally important set of freedoms.

Use of this principle requires three clarifications. First, the distinction between effective and formal freedom. While formal freedom guarantees absence of certain kinds of interference in a given arena, effective freedom guarantees that one can in fact achieve the freedom's object. That is, effective freedom requires access to whatever resources are needed to exercise it. So while a person has formal freedom of movement insofar as the law prevents others from physically restraining her, she does not have effective freedom of movement unless she has either the internal abilities or external assistive technologies to move herself from place to place. Second, note that the principle requires that liberal egalitarian states must guarantee their citizens freedoms only within some centrally important set, the members of which will depend upon the liberal egalitarianism in question. For instance, while a version of comprehensive liberalism might guarantee the effective use of a set of freedoms that it takes to be especially metaphysically valuable, a version of political liberalism might guarantee a set of freedoms centrally important to the roles of citizenship. Third and finally, notice that while liberal egalitarian states have this obligation to citizens, it may in some cases be defeasible. Cases of defeasibility will once again depend on the species of liberal egalitarianism concerned, but the following cases should be illustrative: effective freedoms may be inappropriate for some 
citizens given their capacities (as with children and certain political freedoms); they may be forfeited (as with the criminal who gives up her right to freedom, or the spendthrift who wantonly and repeatedly squanders the resources necessary to exercise another freedom); or their provision may conflict with some other central commitment of the liberal egalitarian state (as in a case in which one citizen's effective use of her religious freedom would require state provision of immense resources that would violate the state's principle of just distribution.)

Given the Effective Freedoms Principle, Rose argues that the state owes citizens a certain quantity of free time. In Rose's words, "An absence of free time constitutes a lack of means in the same way as a lack of income and wealth, and the lack of either renders one less able to take advantage of one's formal liberties and opportunities" (2016: 73). Consider classically guaranteed liberal-egalitarian freedoms: freedom of association, freedom to vote, freedom to hold political office, etc. In order for these rights to be more than formal, one must have both money and time. To run for office, educate oneself about candidates' platforms, or associate with one's fellows, one must have time that is not consumed by finding the basic resources to care for one's own or one's dependents' basic needs. So while the person washing dishes 100 hours per week just to make ends meet may have these formal liberties, he will be unable to exercise them in practice. Contrast this person with the highly-paid psychologist who could support herself by working 20 hours per week but chooses to work 100 because she values great wealth. While her work also leaves little excess time for exercising her liberties, Rose argues that she has the effective option to exercise them in a way that her counterpart does not. ${ }^{2}$ Accordingly, while citizens may choose not to use their free time to exercise their basic liberties, Rose argues that a government that guarantees the effective use of basic liberties must guarantee that citizens have sufficient free time to exercise them after meeting their basic needs.

Note that Rose's project is to show that time - like money - is merely necessary for the effective use of one's freedoms. But the following examples suggest that time and money together are not always sufficient to effectively guarantee persons the freedoms to which they are politically entitled. First, consider Irma, an affluent housewife who believes that a woman's place is in the family. While she could easily afford childcare, a paid cleaning service, or private education, she believes that it would be morally wrong of her to allow her children or home to be cared for by others. Accordingly, she rarely associates with those outside of her family

2 See the distinction between free and necessary time: Rose (2016: 40-43). 
even when she might like to, does not engage in politics, etc. Second, consider Harvey, who is part of a reclusive religious community. While Harvey lives a comfortable life with much time for leisure, he believes that engaging with politics is sinful. There is an important sense, I argue, in which both Irma and Harvey lack effective freedom to exercise their basic liberties. While each is aware of their politically-guaranteed freedoms and has the time and monetary resources to exercise them, neither feels morally entitled to do so.

The point is not merely that Irma and Harvey refrain from exercising their rights, since most of us refrain at many points from exercising them. The point is rather that both Harvey and Irma take there to be a categorical, substantive obstacle to their exercising some of their most basic politically-guaranteed rights. To be sure, the obstacle in question is internal - each recognizes that no external party or lack of resources prevents them from exercising those rights. But each, given their central commitments, also recognizes that exercising those rights is not an option that is substantively available to them. And note that we cannot say that the obstacle does not exist, simply because neither Irma nor Harvey has the aim of exercising those freedoms. An inaccessible building does not stop being effectively inaccessible to a person who uses a wheelchair simply because she does not want to enter it. Like the wheelchair user, Harvey and Irma do not just take themselves to be in a position where they do not choose to exercise their freedom. Rather, by their own lights, each cannot. The wheelchair user's obstacle is the building's lack of ramps. For Irma and Harvey, the obstacle is the belief and the concomitant feeling that they are not morally entitled to exercise those freedoms. While neither Irma nor Harvey may be bothered by this obstacle, given the desires they actually have, it remains the case that each one's lack of a sense of their own moral entitlement to exercise their basic liberties remains a substantive obstacle to that exercise.

My claim, then, is that an absence of this sense of moral entitlement, like an absence of free time, compromises the effective use of one's basic freedoms. Given the Effective Freedoms Principle, this claim in turn suggests that liberal egalitarian states have an obligation to remove this obstacle. But here we must be careful. By virtue of their liberalism, liberal egalitarian states also have a commitment to some degree of neutrality between conceptions of the good. Different versions of liberalism will again conceive of this commitment to neutrality differently, but all should agree that within at least some range, the state should not favor some lives citizens might choose over others. Comprehensive liberals will likely draw this sphere of neutrality fairly narrowly, limiting it to 
valuable, autonomously-chosen lives (i.e. Raz 1986). Political liberals, alternatively, will likely include any of those lives that recognize political values and respect the rights of all citizens (i.e. Rawls 1993). But note that as described Irma and Harvey's commitments could both fit at least into the political liberal's sphere of neutrality, and might even fit into the comprehensive liberal's. So if my claim about a sense of moral entitlement and effective freedom is correct, we are left here with a conflict between the Effective Freedoms Principle and a liberal commitment to neutrality.

Given the length and focus of this paper, I cannot attempt to fully adjudicate this conflict. Indeed, there is a history of serious objections to the removal of internal obstacles to freedom that dates back at least to Isaiah Berlin (1969). But remember, my aim here is modest: I simply aim to use Rose's framework to give an initial account of whether some other good - that is, a sense of moral entitlement - might, like free time, both prove necessary to guarantee effective freedom of basic liberties, and meet the criteria for being a resource distributable by a liberal egalitarian state. Whether or not - and indeed how - this obstacle ought to be removed, I hope to have at least motivated the idea that it constitutes a real obstacle to the effective use of one's basic liberties. Accordingly, I will turn shortly to the criteria for resources appropriate for distribution by a liberal egalitarian state.

Nevertheless, while I cannot fully adjudicate the conflict here, let me at least briefly suggest how a liberal aiming to balance effective freedom and neutrality might move forward. Imagine that Irma and Harvey developed their comprehensive doctrines quite differently: while Irma adopted hers as an adult after a period in which she felt morally entitled to exercise her basic liberties, Harvey adopted his without having considered or been exposed to alternatives, as a result of growing up in a relatively homogenous community. One plausible method for balancing commitments to effective freedoms and neutrality is to treat these cases very differently. While Irma experienced a period in which she took there to be no obstacle to the exercise of her basic liberties, Harvey never experienced a similar period of effective freedom. Furthermore, even if Irma currently views her moral commitments as closed to revision, the fact that they have already undergone a significant change means that she has a first-hand understanding of the way in which commitments might change with time and new experience. So even if Irma and Harvey's comprehensive doctrines both compromise their effective freedom to exercise basic liberties in the moment, Irma's one-time possession of a sense of moral entitlement to exercise them leaves her better-placed to experience effective freedom again in the future. While fostering an early 
sense of moral entitlement does not then guarantee effective freedom to exercise basic liberties throughout the course of a lifetime, it both allows citizens to adopt a wide variety of comprehensive doctrines in adulthood, and makes more provisional the internal obstacles to effective freedom that those doctrines might include.

\section{A SENSE OF MORAL ENTITLEMENT AS A RESOURCE}

As I said, Rose's strategy in Free Time is to show that free time is both necessary for the effective use of persons' basic liberties, and meets the criteria for being a resource that a liberal egalitarian government can distribute among its citizens. If a sense of moral entitlement, like time, is necessary for the effective use of one's basic liberties, then we should now turn to the question of whether it meets the criteria for counting as a resource in a liberal egalitarian state.

Before we do so, however, we should further specify what we mean by a sense of moral entitlement. While the examples of Irma and Harvey motivated the idea that a lack of a sense of moral entitlement can compromise the effective use of one's basic liberties, there are two distinct but related senses of entitlement that could do so. While I won't take a stand here on which is better suited to serve as a resource distributed by a liberal egalitarian state, distinguishing between the two will clarify the discussion that follows. First, one could believe that they are directly morally entitled to exercise their basic liberties. ${ }^{3}$ If persons take themselves to be entitled in this way, and also have sufficient time and monetary resources, then they plausibly have effective use of their formallyguaranteed liberties. But second, one could believe that one is morally entitled to change her conception of the good if appropriate reasons present themselves. Imagine that Harvey never took himself to be directly morally entitled to the exercise of his political liberties - but that, at some relevant point in his development, he did take himself to be morally entitled to adopt other conceptions of the good, including those according to which he would be morally entitled to make use of his political liberties. Although Harvey never felt morally entitled to use the particular goods to which he was politically entitled, he was open to considering reasons to do otherwise,

3 Note that many liberals will hold that the value of basic liberties derives at least in part from the role they play in allowing citizens to live the lives that they themselves take to be valuable. Insofar as other goods (like wealth, income, education, healthcare, etc.) that a liberal state is obligated to fairly distribute to citizens derive their value from the same source, we may want to expand our sense of moral entitlement to include moral entitlement to make use of these other goods as well. However, this further point cannot be addressed here. 
and to changing his view if those reasons proved compelling. While it can be difficult to determine when a person is genuinely open to considering reasons that conflict with their conception of the good, when that bar has been met they plausibly have effective use of their formally-guaranteed basic liberties - as least as long as they also maintain the time and the money to make use of them.

Now let's turn to Rose's framework for determining whether a good counts as a resource to which the citizens of a liberal egalitarian state have a claim. In order for citizens to have such a claim, it must first be the case that it is appropriate for a liberal egalitarian state to distribute the good in question, given liberal egalitarianism's distinctive commitments. It must second be the case that the good in question can be effectively and justly allocated, given the nature of the good.

\subsection{Is a sense of moral entitlement an all-purpose good?}

I accept Rose's standard formulation of liberal egalitarianism's two distinctive commitments: the liberal commitment to individual freedom of choice, and the egalitarian commitment to ensuring some degree of equality in the distribution of society's benefits (2016: 23). But these principles stand in some tension, since individuals freely choosing life paths will likely end up with shares of goods that are different in both size and kind. For instance, if my idea of a good life involves world travel while my neighbor's involves investment in real estate, we will likely end up with very different shares of exciting stories and vacation properties. Accordingly, I also accept along with Rose the standard liberal egalitarian position that states should be concerned with the distribution of allpurpose goods that individuals can use to advance their conceptions of the good, rather than the specific goods that their conceptions of the good direct them to attain. In her words, "specific goods are the particular goods that one requires to pursue one's particular conception of the good, whereas resources are all-purpose means that one generally requires to pursue one's conception of the good, whatever it may be" (2016:27, original emphasis). A yacht, then, counts as a specific good that might feature prominently in some good lives but have no place in others, while wealth and income count as all-purpose goods because they can equally be used to acquire yachts, leisure time, the ability to support beloved charities, or the specific goods that have a central place in other lives. If the state distributes resources which anyone can use to advance their own idea of a good life, then each citizen can see how her interests are served by that distribution - while if it distributes specific goods valued by only some individuals, then those who do not value those goods have cause for complaint. 
So the first test for a sense of moral entitlement is to determine whether it is an all-purpose good. On the face of it, it does not seem to be. At least, it is clearly not required to pursue all conceptions of the good, no matter what those conceptions may be. Given that both Harvey and Irma have conceptions of the good that can be pursued without exercising at least some of their basic liberties, they also have conceptions of the good that can be effectively pursued without a sense that one is morally entitled to directly pursue those liberties. And while some persons may take the ability to change one's conception of the good to be central to any substantively good life, many more will not - and this large remainder can therefore effectively pursue their conceptions of the good without a sense that they are morally entitled to change them.

But we should not be too quick to judge from this that a sense of moral entitlement is not an all-purpose good. Even wealth and income are not required to pursue literally any conception of the good, whatever that conception may be. Consider the person who takes the good life to be a life of prayer in which one has no possessions and eats only what they are freely given by others. ${ }^{4}$ Since wealth, income, and the basic liberties themselves are the canonical all-purpose goods, we therefore need a different account of what it means to be an all-purpose good. While I don't aim here to defend one account as correct, each of the following three possibilities is both a plausible account of all-purpose goods, and plausibly counts a sense of moral entitlement as an all-purpose good.

First, a good might be all-purpose if it is useful for advancing a broad range of conceptions of the good. This is plausibly what is suggested by Rose's specification that all-purpose goods are those means that are "generally" required to pursue conceptions of the good, whatever they may be. While there may be a few exceptions, advancement of almost all conceptions of the good will benefit from these means. And although it may be possible to advance the majority of conceptions of the good without a sense that one is morally entitled to change that conception of the good, it is much harder to identify conceptions of the good that can be effectively advanced without a sense that one is morally entitled to take advantage of one's basic liberties. And this is because the value of a basic liberty for a conception of the good is generally understood to be instrumental. For many of us, political participation or free speech is not an intrinsically valuable part of a good life. Instead, both allow us to express what we take to be good, or to defend our way of life when it is under attack. But liberties cannot benefit our conceptions of the good in this way unless we exercise

$4 \quad$ For further argument that primary goods are not plausibly means that one wants whatever else they want, see Nelson (2008). 
them - and one is much less likely to actually exercise a liberty that one does not take oneself to be morally entitled to exercise. So since basic liberties will themselves be instrumentally valuable for advancing $a$ broad range of conceptions of the good, the sense of moral entitlement to exercise them will be as well.

Second, a good might count as all-purpose if it is required for developing or protecting the moral powers and interests associated with citizenship. This suggestion aligns with John Rawls's proposal that what is taken to be valuable for citizens relates to the higher-order interests they are taken to have as citizens - including, famously, the capacity for a sense of justice and the capacity to hold and revise a conception of the good. ${ }^{5}$ If we take these to be the relevant interests of citizens, then citizens obviously have an interest in a sense of moral entitlement to change their conception of the good. The ability to do so is central to the second moral power, and it once again frustrates both a capacity and its development when a person feels unentitled to exercise and thereby strengthen that capacity. Similarly, a sense of moral entitlement to directly exercise one's basic liberties plausibly supports the second moral power, because the exercise of those liberties themselves supports that power by allowing citizens to try out and investigate new ways of life that might lead them to adopt new conceptions of the good.

Third, a good might count as all-purpose if it is closely tied to some other value that grounds liberalism's commitments to equality and neutrality. Take, for instance, Alan Patten's claim that the value of both equality and neutrality depend on the more fundamental liberal value of self-determination (2012). If self-determination is at bottom what matters for liberal states, then other resources should be distributed to the extent that they further that value. And a sense of moral entitlement to change one's conception of the good certainly does so. If one feels perpetually bound to one's conception of the good even when compelling reasons to modify it arise, then one plausibly becomes a prisoner to that conception of the good rather than a self-determining individual. Similarly, the basic liberties generally distributed by liberal states very plausibly provide persons with essential freedoms and means to live their lives as they see fit - but they once again do so instrumentally, and their instrumental benefit again generally only accrues if one feels entitled to make use of them when the need for them arises.

$5 \quad$ See also Gina Schouten's (2017) argument that protection of the two moral powers often in fact demands substantive progressive interventions on the part of liberal egalitarian states - up to and including preserving a live option for all citizens to engage in genderegalitarian division of household labor. 
While this discussion by no means exhausts the ways in which we could understand all-purpose goods, each is plausible - and each gives us a plausible reason to think that the sense of moral entitlement with which we are concerned is the kind of thing that ought to count as an all-purpose good.

\subsection{Can entitlement be effectively and justly allocated?}

In order to count as a resource using Rose's criteria, an all-purpose good must also be the kind of thing that satisfies the following publicity and feasibility criteria (2016: 46):

Publicity Criterion: It must be possible for an outside party to reliably and verifiably know whether and to what extent an individual possesses a given resource.

Feasibility Criterion: It must be possible for the outside party to obtain relevant knowledge and distribute the good non-invasively and efficiently.

The publicity criterion applies because in order for justice to be done, citizens must be able to see that it has been done. If a resource is not the kind of thing that can reliably be measured, then citizens cannot know whether a just distribution has been achieved. And the feasibility criterion applies because efficiency and privacy matter alongside publicity. If enormous resources must be expended to monitor or fairly distribute a good, or if that monitoring and distribution comes at the cost of citizens' reasonable expectation of privacy, then these considerations count heavily against treating that good as a resource that a just state ought to distribute.

To illustrate, consider health. While health is required to pursue almost any conception of the good, it is not always possible to adequately judge relative shares of health. This is so both because different definitions of health better capture the health level of different individuals, and because health is not a free-floating concept that makes sense without reference to the state of a population. Further, in order to monitor and influence the distribution of health among citizens even according to some stipulated definition, the state would need to engage in frequent and highly intrusive testing and treatment of individuals. Health, then, will not count as a resource on Rose's criteria. But note that a nearby good - that is, healthcare - can still count. Since healthcare is required to protect health when it fails, and since failing health threatens the ability to pursue almost any conception of the good, healthcare is what Samuel Arnold calls a 
"second-order all-purpose [good]" (2012: 97). ${ }^{6}$ A second-order all-purpose good is one that is "instrumental to the possession of entities or attributes that are themselves all-purpose [goods]". And the second-order allpurpose good of healthcare satisfies publicity and feasibility criteria. Regarding publicity, it is possible to know both what coverage citizens have for which medical conditions, and whether citizens live within appropriate proximity to medical establishments. And regarding feasibility, that information can be collected and the good can be provided both noninvasively and efficiently. By providing universal healthcare or enforcing an individual mandate, states can both ensure the provision of care and non-invasively and efficiently gather information about what coverage individuals have; and by determining a citizen's address and whether relevant public transportation is available, states can non-invasively and efficiently gather information about whether citizens can effectively seek treatment.?

We must determine, then, whether a sense of entitlement satisfies the publicity and feasibility criteria. First, consider publicity. It is highly likely that there is no fully verifiable and reliable way for third parties even in theory to accurately determine and compare persons' comparative shares of a sense of moral entitlement. Citizens may understand their degrees of entitlement very differently, and even when they report the same rating, the scales that they use may be incommensurable. And turning to feasibility, even if these obstacles could be overcome, making such comparisons in practice would require extensive and invasive questioning of persons, as well as time- and resource-intensive calculations to determine citizens' relative scores.

Two different responses might be made by proponents of treating a sense of moral entitlement as a resource. The first is to identify a secondorder all-purpose good associated with the sense of moral entitlement. This approach follows Rawls' precedent of including "the social bases of self-respect" rather than self-respect itself in his list of primary goods (1999). If a particular set of social conditions roots and reliably fosters the relevant sense of moral entitlement, and that set of social conditions passes the publicity and feasibility conditions, then we could count that set of social conditions as our resource. While it is in large part an empirical matter whether some set of conditions roots and reliably fosters a sense of moral entitlement, it seems prima facie likely that the conjunction of some

6 While Arnold calls such goods all-purpose "resources" I call them goods and with Rose - reserve the term resource for goods that meet all of our criteria.

7 To be sure, there are many important social determinants of health, of which healthcare is only one. I leave open the question of whether these other determinants satisfy the publicity and feasibility criteria. 
standard of formal education and broad exposure to persons living diverse lives would do so. The more that one enjoys close connections with those living diverse lives, and comes to appreciate their reasons for holding different conceptions of the good, the more likely they will be to see as morally legitimate the choice to hold another conception of the good or to make use of the resources and liberties used by one's peers. And a third party can certainly verifiably and reliably determine whether citizens are enrolled in these kinds of education and live in diverse communities. Gathering this information should also be relatively efficient and noninvasive, since it will primarily require consulting census data and curricular data that are already collected. And states clearly have at their disposal resources for effectively determining curricular standards and encouraging diverse neighborhoods.

The other response is to reject the move to second-order all-purpose goods on the grounds of the type of resource that a sense of moral entitlement is. Here Rose's treatment of free time is once again illuminating. As Rose argues, the appropriate distributive principle may vary from resource to resource, depending on each resource's nature (2016: 85ff). Take Rose's comparison of inequalities in time and material wealth. Inequalities in either domain can be problematic from the point of view of justice, because either can lead to social inequalities between citizens. But there are two reasons to think that inequalities in wealth are more worrisome than inequalities in free time. First, there is a natural limit to inequalities in free time that does not hold in the case of wealth (2016: 87). While the potential difference between the wealthiest and poorest subject is virtually limitless, inequalities between the most time-rich and timepoor citizens can vary by at most a few hours in a given day. After all, some kinds of self-maintenance simply cannot be outsourced. ${ }^{8}$ So to the extent that equality of resource directly translates into social inequality, inequalities of time simply allow for a lower degree of inequality. Second, material wealth can be more efficiently converted into other kinds of basic goods than can time (2016: 88 ). For instance, a person with a comparatively large share of free time can use that time to undertake additional paid work or petition her lawmakers, thereby gaining additional income or political influence. But she must do so in real time, and cannot readily trade her free time with others who will advance these ends for her. However, a person with a comparatively large share of wealth can readily trade that wealth for a great variety of other goods: for the consumer goods that signal social class, for the elite education that cements one's children's

8 While these differences could compound over a lifetime, the degree of inequality possible for time could never approach the degree of inequality possible for wealth. 
high social position, or for the political influence that lobbyists and large campaign contributions can buy. Both of these differences suggest that a sufficiency principle might effectively protect social equality in the case of time but not wealth. While either can be used to attain a set of additional goods that negatively impact social equality, time is converted into these additional goods much less efficiently, and the limits on the time that one can have to convert are furthermore much stricter.

With regards to distributive principles, a sense of moral entitlement to use one's basic liberties seems to be more like free time than like money. While persons might have stronger and weaker senses of moral entitlement, our focus here is on the effect of a sense of moral entitlement on the effective use of one's basic liberties. And this effect is plausibly binary: one may exercise one's basic liberties hesitantly or enthusiastically, but what matters for advancing one's plan of life is that one does in fact exercise them when the situation calls for it. Beyond the threshold that allows one to exercise one's basic liberties, having a stronger sense of moral entitlement to do so does not seem to make a person substantially better able to exercise them than her fellow citizens. What does this mean for the appropriate distributive principle for our sense of moral entitlement? Remember that sufficiency was meant to be a more plausible distributive principle for time than for money on the grounds that unchecked inequalities in money allow greater corresponding inequalities between citizens. If one does not become substantially better able to exercise her basic liberties the more morally entitled she feels to do so, then sufficiency is also a plausible distributive principle for our sense of moral entitlement.

Determining whether this seemingly plausible claim holds would require space for further defense. But if it held, then a focus on sufficiency should make both the publicity and the feasibility criteria easier to satisfy. First, consider publicity. Unlike determining comparative shares, determining sufficiency would no longer imply comparing persons' relative levels of the sense of moral entitlement, or the conceptual and practical problems that come with it. Instead, it would simply require determining whether each person takes herself to be able to choose to exercise her basic liberties if reasons to do so arise - and this can be determined through simple self-reporting. And if we diffuse the tension between the Effective Freedoms Principle and a commitment to liberal neutrality in the way suggested above, then a concern with sufficiency would also make the feasibility criterion easier to satisfy. If we aimed to ensure only a sufficient sense of moral entitlement during early life, then the relatively undemanding self-reporting required to determine sufficiency could be built into public education at regular intervals without 
great cost. And if we were concerned with a threshold level of a sense of entitlement rather than a comparative level, then public education could aim to bring all students past the line without worrying that some will progress significantly further than others.

\section{CONCLUSION}

As noted at the outset, the argument offered here is initial and cursory, and many objections and important subtleties have by necessity been passed over.9 But I hope that the discussion so far has served my modest aim: to begin to show us how we might extend Rose's helpful framework to offer a treatment of other under-explored or under-theorized resources that a liberal egalitarian state owes its citizens. I hope that it has also encouraged readers to believe that a sense of moral entitlement to exercise one's basic liberties is one such resource worth exploring - and if so, then I hope that Rose's framework can serve to illuminate a longer (perhaps also booklength) treatment of that resource in the future.

\section{BIBLIOGRAPHY}

Arnold, S., 2012: “The Difference Principle at Work”, Journal of Political Philosophy 20: 94-118.

Berlin, I., 1969: “Two Concepts of Liberty”, in Four Essays on Liberty, Oxford: Oxford University Press.

Nelson, E., 2008: "From Primary Goods to Capabilities: Distributive Justice and the Problem of Neutrality”, Political Theory 36: 93-122.

Patten, A., 2012: "Liberal Neutrality: A Reinterpretation and Defense", Journal of Political Philosophy 20: 249-272.

Rawls, J., 1993: Political Liberalism, New York: Columbia University Press.

- 1999: A Theory of Justice: Revised Edition, Cambridge, Mass: The Belknap Press of Harvard University Press.

Raz, J., 1986: The Morality of Freedom, Oxford: Clarendon Press.

Rose, J.L., 2016: Free Time, Princeton: Princeton University Press.

Schouten, G., 2017: "Citizenship, reciprocity, and the gendered division of labor: A stability argument for gender egalitarian political interventions", Politics, Philosophy \& Economics 16: 174-209.

9 In particular, I take it that a fuller treatment of the relationship between selfrespect and entitlement is warranted, as the two goods may overlap depending on our account of each. Briefly, insofar as Rawls's discussion of self-respect focuses on the extent to which citizens see themselves as capable of carrying out conceptions of the good that they take to be worthwhile, I believe that we need either a broader account of the importance of self-respect or a separate discussion of entitlement to do justice to entitlement as a resource. Either way, more work remains to be done. 